\title{
Pengaruh Daya Saing, Budaya Keuangan, dan Keputusan Pembayaran Kredit Terhadap Akses Keuangan
}

\author{
Hadi Ismanto*1), Sri Hartanti*, Diana Anjar Wulan*, Durrotul Mustagfiroh*, Alfendo \\ Andrian Nofian* \\ ${ }^{*}$ Program Studi Manajemen, Fakultas Ekonomi dan Bisnis, \\ Universitas Islam Nahdlatul Ulama Jepara \\ Jl. Tamansiswa no. 9 Tahunan, Jepara, Jawa Tengah, 59451 \\ ${ }^{1)}$ Email penulis korespondensi: hadifeb@unisnu.ac.id
}

\begin{abstract}
ABSTRAK
Beberapa studi empiris selama satu dekade terakhir menunjukkan bahwa akses ke keuangan merupakan kendala UKM untuk tumbuh. Melihat kondisi ini, OJK menetapkan peraturan terkait dengan pembiayaan online UKM (equity crowdfunding) yang tengah boom di dunia keuangan. Penelitian ini menganalisis pengaruh daya saing, budaya keuangan, dan keputusan pembayaran kredit terhadap akses ke keuangan. Pengambilan sampel didasarkan pada jenis industri kecil dan menengah. Data dikumpulkan dari penyebaran kuesioner terhadap 285 UKM di Jepara menggunakan pendekatan door to door dan pendampingan pengisian. Data diuji statistik untuk analisis deskriptif, validitas dan reliabilitas, dan regresi linear. Hasil penelitian menunjukkan adanya pengaruh positif dari daya saing, budaya keuangan, dan keputusan pembayaran kredit terhadap akses UKM ke keuangan. Temuan ini menunjukkan pentingnya daya saing dan budaya keuangan UKM untuk mengakses pendanaan eksternal. UKM dapat memperbaiki/meningkatkan kapasitas dan kemauan mereka untuk mengajukan pendanaan. Hasil penelitian juga memberikan kontribusi literasi di bidang keuangan terkait dengan aksesibilitas UKM ke pembiayaan dan keputusan pembayaran kredit, daya saing, serta budaya keuangan.
\end{abstract}

Kata kunci: Akses Keuangan; Budaya Keuangan; Daya Saing; UKM.

\footnotetext{
ABSTRACT

Several empirical studies over the past decade have shown that access to finance is an obstacle for SMEs to grow. So that OJK establishes regulations related to SMEs equity crowdfunding, which can be accessed by all SMEs in Indonesia. This study
} 
analyzes the influence of competitiveness, financial culture, and credit payment decisions on access to finance. Sampling based on the type of small and medium industries. Data were collected from distributing questionnaires to 285 SMEs in Jepara using a door-to-door approach and filling assistance. Data were tested statistically for descriptive analysis, validity and reliability, and linear regression. The results showed that there was a positive influence on competitiveness, financial culture, and credit payment decisions on SMEs' access to finance. These findings indicate that competitiveness and financial culture are important to accessing external funding. SMEs can improve/increase their capacity and willingness to apply for funding. These results also contribute to literacy in the financial sector related to the accessibility of SMEs to financing and credit payment decisions, competitiveness, and financial culture.

Keyword: Access to Finance; Financial Culture; Competitiveness; SME.

\section{PENDAHULUAN}

Usaha kecil dan menengah (UKM) telah menjadi bagian penopang ekonomi nasional, namun permasalahan klasik dalam pengembangan, pertumbuhan, keberhasilan dan kinerja UKM adalah kurangnya akses ke layanan keuangan terutama lembaga formal (baik bank atau non bank) (Ahiawodzi \& Adade, 2012; Angilella \& Mazzù, 2015; Fowowe, 2017; Ikasari et al., 2016; Machmud \& Huda, 2011). Ketersediaan keuangan telah disorot sebagai faktor utama dalam keberhasilan dan kinerja UKM. Masalah akses ke sumber keuangan untuk UKM ada ketika kegiatan bisnis yang akan dibiayai secara internal tidak mendapatkan dukungan dari lembaga keuangan eksternal.

Lebih dari 58\% Produk Domestik Bruto (PDB) Indonesia ditopang dari UKM dan mampu menyerap tenaga kerja hingga 97\%. Prospek usaha kecil dan menengah perlu ditingkat terus menerus untuk kesejahteraan masyarakat dan pertumbuhan ekonomi. Sebagai salah satu negara berkembang, akses ke keuangan merupakan cerminan dari efektivitas kebijakan pemerintah. Bagi UKM, akses ke keuangan merupakan faktor pendorong pertumbuhan (Adomako et al., 2015; Ahiawodzi \& Adade, 2012) dan kinerja usaha (Fowowe, 2017; Harash et al., 2014). Namun, akses ke keuangan masih menjadi kendala utama keberlanjutan bisnis (Lee et al., 2013, 2015; Venturelli, 2008). Penyerapan pembiayaan bagi UKM di Indonesia masih tergolong sangat rendah. Berdasarkan data yang diperoleh dari website resmi Otoritas Jasa Keuangan (OJK) Republik Indonesia per Oktober 
2019 menunjukkan hanya sebesar 15,58\% atau senilai 72.949 miliar rupiah pembiayaan yang berhasil diserap oleh UKM. Penyerapan itu masing-masing adalah 4,32\% atau senilai 20.244 miliar rupiah oleh usaha kecil dan $11,26 \%$ atau senilai 52.705 miliar rupiah oleh usaha menengah.

Angka penyerapan ini menunjukkan bahwa UKM masih kesulitan untuk mengakses pembiayaan ke lembaga keuangan. Minimnya penyaluran pembiayaan karena terkendala administrasi dan manajemen keuangan UKM yang rendah. Pemerintah mulai memberikan perhatian khusus kepada pelaku usaha kecil dan menengah dalam kemudahan akses ke lembaga keuangan dengan upaya koordinasi bersama bank-bank untuk memfasilitasi Kredit Usaha Rakyat (KUR). Bahkan, kebijakan equity crowdfunding resmi dirilis oleh OJK dalam rangka membantu UKM memperoleh dana melalui penawaran saham berbasis teknologi. Namun, faktor-faktor internal perusahaan yang menunjukkan kualitas dan fleksibilitas keuangan bisnis juga perlu untuk dianalisis.

Dalam penelitian ini mencoba berkontribusi pada literatur dengan menyelesaikan masalah dari sudut pandang yang berbeda. Tidak dapat dipungkiri bahwa UKM juga memerlukan pembiayaan untuk membiayai dan memperluas bisnis mereka. Namun, untuk melakukannya UKM sering kali kesulitan mengakses ke layanan keuangan karena terjadinya kesenjangan keuangan (Machmud \& Huda, 2011). Lembaga keuangan formal mengklasifikasikan UKM sebagai perusahaan unbankable. Terlepas dari itu, pinjaman bank adalah sumber pendanaan eksternal yang penting bagi UKM. Penelitian ini mencoba menganalisis faktor-faktor apa yang dapat mempengaruhi aksesibilitas UKM ke layanan keuangan. Beberapa studi empiris mendokumentasikan ada perbedaan antara pemilik lakilaki dan pemilik perempuan dalam mengakses layanan keuangan (Arenius \& Autio, 2006; Gazanchyan et al., 2017; Scott \& Irwin, 2007; Treichel \& Scott, 2006; Wellalage \& Locke, 2017). Namun, faktor-faktor kepribadian tidak dipertimbangkan disana. Untuk itu penelitian ini mencoba menganalisis faktor daya saing, budaya keuangan, dan keputusan pembayaran kredit terhadap peluang akses ke layanan keuangan.

Akses ke keuangan mengacu pada kemungkinan bahwa individu atau perusahaan dapat mengakses layanan keuangan (Mertzanis, 2017). Akses keuangan sangat penting untuk penyediaan keuangan yang efektif untuk pengembangan perusahaan dan memungkinkan perusahaan untuk tumbuh dengan mengeksploitasi pangsa pasar dan peluang investasi. Pada gilirannya, membawa manfaat bagi ekonomi dengan mempercepat pertumbuhan ekonomi, mengintensifkan persaingan, serta meningkatkan pendapatan mereka dan mengurangi 
kemiskinan. Akses ke keuangan adalah kemampuan individu atau perusahaan untuk mendapatkan layanan keuangan, seperti kredit, deposito, payment, asuransi dan layanan lainnya (Demirgüç-Kunt et al., 2008). Menurut Ikasari et al., (2016), mudah atau tidaknya akses ke keuangan dapat dilihat dari 2 aspek yaitu aksesibilitas, kelayakan, dan keterjangkuan/kemampuan. Aksesibilitas yaitu kedekatan jarak rumah atau perusahaan dengan bank serta kemudahan mengakses ke tujuan. Sedangkan kelayakan kredit diukur melalui pengetahuan pemilik UKM terhadap berbagai layanan keuangan yang ditawarkan oleh bank beserta prosedur permohonan kredit dan kemampuan untuk menyediakan jaminan serta seluruh dokumen yang dibutuhkan untuk permohonan kredit. Untuk keterjangkauan kredit dilihat dari kemudahan UKM untuk menyediakan dokumen yang dibutuhkan untuk permohonan kredit dan keterjauan tingkat bunga kredit.

Persaingan bisnis semakin kompleks, bahkan pemilik sering kali melakukan berbagai cara agar dapat mempertahankan bisnisnya. Kemampuan itulah yang disebut daya saing (Ahmedova, 2015). Ceptureanu (2015) mendefinisikan daya saing sebagai konsep multidimensi yang ditentukan oleh sumber daya, proses menggunakan sumber daya, dan faktor lingkungan. Masing-masing sumber daya perusahaan - manusia, informasi, teknis, dan keuangan memiliki ukuran, komponen dan karakteristik yang mempengaruhi daya saing UKM. Di tingkat kecil, tingkat daya saingnya dapat dilihat dari kualitas produk dan layanan, kemampuan untuk menghasilkan nilai tambah, praktek manajemen mutu, dan sikap terhadap budaya organisasi. Sedangkan daya saing di tingkat menengah melalui profesionalitas, kompetensi, dan pangsa pekerja. Untuk mencapai tujuan bisnis, sumber daya harus diproses untuk meningkatkan daya saing bisnis.

UKM berdaya saing tinggi cenderung lebih mudah beradaptasi dengan kondisi ekonomi negara dan perubahan pasar, ini berdampak positif terhadap produktivitas bisnis (Ahmedova, 2015; Laureti \& Viviani, 2011; Wysokińska, 2003). Daya saing yang lebih sukses di persaingan pasar dapat membawa peningkatan jangka panjang dalam kualitas hidup dan penciptaan lapangan kerja. Pada akhirnya, berdampak pada produktivitas yang lebih tinggi dan menawarkan keunggulan kompetitif yang lebih baik, yang dengan demikian perusahaan dapat lebih mudah dalam mengakses layanan keuangan.

Di era persaingan ini, UKM menghadapi tiga tantangan yaitu bagaimana meningkatkan kinerja UKM, meningkatkan daya saing individu, dan memanfaatkan sinergi yang diciptakan dalam jaringan UKM (Karaev et al., 2007). Potensi untuk mencapai produktivitas yang tinggi dapat digapai ketika UKM mampu bersaing dengan keunggulan kompetitif (Laureti \& 
Viviani, 2011; Wysokińska, 2003). Peningkatan daya saing UKM ditentukan oleh tingkat pendidikan, modal kerja, tingkat inovasi dan strategi bisnis yang dapat mempengaruhi kinerja bisnis (Anton et al., 2015) dan produktivitas perusahaan (Laureti \& Viviani, 2011; Wysokińska, 2003). Sedangkan Carvalho \& Costa (2014) menyebutkan bahwa daya saing UKM dapat dilihat dari pendapatan, ekspor, keuntungan, pangsa pasar, produktivitas, nilai perusahaan, kepuasan pelanggan, nilai produk dan jasa. Meskipun begitu, keduanya sebagai bahwa UKM yang berani bersaing dan mampu bertahan di persaingan yang ketat akan berpotensi untuk terus tumbuh. UKM yang berdaya saing tinggi cenderung menunjukkan kinerja dan produktivitas yang lebih baik dibandingkan UKM yang berdaya saing rendah. Dengan performa bisnis yang baik dan unggul, lembaga keuangan akan tertarik untuk memfasilitasi pembiayaan kepada UKM sehingga akses UKM ke keuangan dapat diperoleh.

Budaya tumbuh dan menjadi suatu kebiasaan dalam lingkungan perusahaan. Setiap perusahaan memiliki budaya masing-masing dimana karyawan berusaha mengikuti aturan yang sama untuk mencapai tujuan yang sama. Nilai-nilai budaya penting dalam pengambilan keputusan keuangan (Breuer \& Quinten, 2009) dan keputusan investasi (Statman, 2008). Di bidang keuangan, budaya keuangan berorientasi untuk menjaga kesehatan keuangan termasuk perencanaan dan perkiraan keuangan. Tingkat pembentukan dan penggunaan budaya keuangan di perusahaan memiliki kepentingan besar bagi pengembangan perusahaan. Budaya itu termasuk perencanaan keuangan, perkiraan pendapatan dan pengeluaran, dan perilaku keputusan pembayaran pinjaman. Csiszárik-kocsir, Varga, \& Fodor (2016) mendefinisikan budaya keuangan sebagai keterampilan mengelola keuangan, keterampilan itu terdiri dari pengetahuan, rasionalitas dan kesadaran keuangan. Nilai-nilai budaya keuangan mencerminkan perilaku keuangan (Breuer \& Quinten, 2009).

Budaya keuangan terdiri dari beberapa aspek yaitu kesejahteraan keuangan, perilaku keuangan, sikap keuangan, perspektif waktu dan kemampuan untuk menunda kepuasan (Zsótér, 2018). Elemen-elemen ini tidak mencakup seluruh definisi budaya keuangan, tetapi elemen-elemen tersebut sangat penting dalam budaya keuangan perusahaan. Rumyantseva (2013) menyebutkan tingkat budaya keuangan adalah kunci kesejahteraan keuangan dan peningkatan produktivitas perusahaan. Dengan demikian budaya keuangan yang buruk menyebabkan terjadinya inefisiensi transaksi keuangan yang mana menunjukkan kualitas manajemen keuangan yang buruk. Keadaan yang buruk tersebut akan terbaca oleh lembaga keuangan dan menghambat akses pembiayaan perusahaan.

Perilaku kredit UKM akhir-akhir ini sering dibahas sebagai fitur pengukur risiko kredit 
UKM (McHugh \& Ranyard, 2012, 2016; Mutegi et al., 2015; Siddiqui, 2017; Wang, 2012). Perilaku pembayaran pinjaman yang buruk merupakan masalah utama yang dihadapi oleh kebanyakan lembaga keuangan (Siddiqui, 2017). Faktor pembayaran pinjaman terdiri dari tiga pelaku yaitu karakteristik peminjam, perusahaan, dan pemberi pinjaman (Siddiqui, 2017). Studi tersebut menunjukkan bahwa ketika pinjaman tidak dilunasi, itu mungkin akibat ketidakmauan peminjam atau ketidakmampuan untuk membayar. Riset yang dilakukan oleh Ismanto \& Diman (2014) menyebutkan bahwa efektivitas pemberian pinjaman kepada UMKM dipengaruhi oleh pendapatan usaha, lama usaha, dan nilai pinjaman. Selain itu, persyaratan agunan dan kecukupan jumlah pinjaman juga merupakan faktor penting yang mempengaruhi perilaku pembayaran. Karakteristik peminjam termasuk didalamnya perilaku membayar berhubungan dengan keputusan pembayaran pinjaman. Berdasarkan model mekanisme, fitur kredit pengusaha diperlakukan dalam dua aspek yaitu kapasitas kredit dan kemauan kredit (Wang, 2012). Karakter-karakter dasar kedua aspek tersebut mewakili perilaku pemilik, dan selanjutnya berdampak pada risiko kredit perusahaan. Kapasitas kredit seperti pendapatan usaha dan kemampuan menangani kesulitan keuangan akan menentukan keputusan pembayaran kredit.

Mutegi et al., (2015) menyebutkan bahwa ada empat keterampilan yang harus dimiliki UKM dan sangat menentukan UKM untuk membayar pinjamannya, empat keterampilan itu meliputi manajemen kredit yang yang tepat, keterampilan pembukuan, keterampilan penganggaran, dan keterampilan analisis keuangan. Kombinasi keempat keterampilan tersebut akan membantu UKM untuk mengambil keputusan pembayaran kredit. Manajemen kredit yang tepat akan dapat memberikan informasi kredit perusahaan termasuk biaya pinjaman, ukuran pinjaman, tingkat bunga dan informasi lainnya. McHugh \& Ranyard (2012, 2016) menyebutkan bahwa keputusan pembayaran pinjaman memiliki efek signifikan terhadap tingkat pembayaran pinjaman. Keputusan pembayaran cicilan secara rutin menunjukkan UKM memenuhi kewajibannya dengan baik sehingga tingkat pembayaran pinjamannya terjamin. Tingkat pembayaran yang rendah cenderung akan mengurangi kepercayaan bank untuk memberikan pinjaman kepada UKM tersebut. Yang dengan demikian, akses ke layanan keuangan menjadi terhambat.

Kajian literatur dan fenomena yang terjadi memunculkan satu pertanyaan penelitian, apa yang menyebabkan akses ke keuangan UKM lebih sulit? Oleh kaena itu, penelitian ini bertujuan untuk menganalisis pengaruh daya saing, budaya keuangan, dan keputusan UKM untuk pembayaran kredit terhadap akses ke keuangan baik secara parsial maupun simultan. 
Dengan demikian, memunculkan hipotesis penelitian di bawah ini:

H1: Ada pengaruh daya saing UKM terhadap akses ke keuangan

H2: Ada pengaruh budaya keuangan UKM terhadap akses ke keuangan

H3: Ada pengaruh keputusan UKM untuk pembayaran kredit terhadap akses ke keuangan

\section{METODE PENELITIAN}

Penelitian ini menggunakan pendekatan kuantitatif untuk menguji data primer. Data diperoleh melalui hasil kuesioner yang telah diisi oleh pengusaha UKM di Kabupaten Jepara. Peneliti mengunjungi pengusaha UKM secara langsung (door to door) untuk meminta kesediaan mengisi kuesioner. Penelitian dilakukan selama bulan Maret 2019 hingga Maret 2020. Pengambilan sampel menggunakan metode proportional random sampling berdasarkan jenis industri kecil dan menengah. Jumlah sampel ditentukan berdasarkan rumus Slovin dengan tingkat kesalahan 5\% dari jumlah populasi UKM di Jepara sebanyak 18.695 unit usaha dan dihasilkan 386 unit usaha. Namun dalam perjalanannya, hanya sebanyak 317 kuesioner yang berhasil dikumpulkan dan 285 diantaranya dinyatakan valid. Jumlah ini yang selanjutnya digunakan dalam analisis deskriptif dan regresi. Data diolah menggunakan perangkat lunak Smart-PLS untuk beberapa uji statistik meliputi analisis deskriptif, uji validitas dan reliabilitas, dan pengujian hipotesis.

Variabel penelitian antara lain akses ke keuangan (ACC), daya saing (TIV), budaya keuangan (CUL), dan keputusan pembayaran kredit (REY) sebagaimana dalam Gambar 1. Variabel dependen penelitian ini adalah akses ke keuangan yang mengacu pada Ikasari et al. (2016). Variabel akses ke keuangan dilihat dari tiga indikator yaitu aksesibilitas, keterjangkauan dan kelayakan. Untuk daya saing diukur menggunakan indikator dari Carvalho \& Costa (2014) yaitu pendapatan, pangsa pasar, kepuasan, nilai perusahaan dan nilai produk/jasa yang semuanya dirangkum dalam lima pertanyaan. Pengukuran variabel budaya keuangan mengikuti item yang digunakan oleh Rumyantseva (2013). Ada enam pertanyaan untuk variabel ini meliputi budaya dalam proses keuangan, komunikasi, pemetaan pasar, pemahaman konsep keuangan, laporan keuangan dan penetapan target. Untuk variabel keputusan pembayaran kredit mengadopsi indikator McHugh \& Ranyard (2016) dan enam pertanyaan mewakilinya. Penilaian variabel-variabel penelitian menggunakan skala skor 1 sampai 6. Untuk pertanyaan positif, 1 skor untuk "sangat tidak setuju" dan 6 skor untuk "sangat setuju". Sedangkan untuk pertanyaan negatif, 1 skor untuk "sangat setuju" dan 6 skor untuk "sangat tidak setuju". 


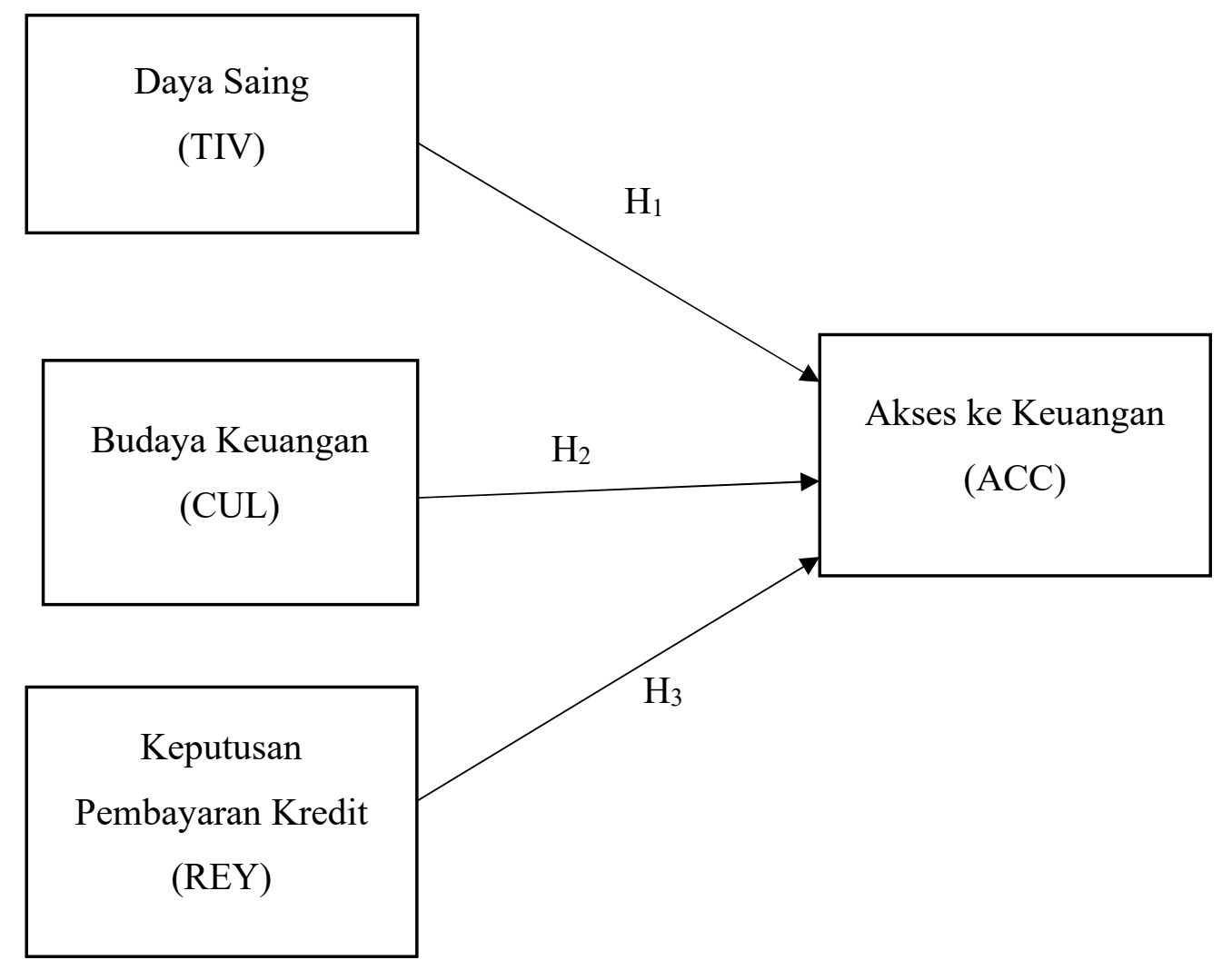

Gambar 1. Kerangka Penelitian

\section{HASIL DAN PEMBAHASAN}

Instrumen penelitian diuji validitas dan reliabilitas terlebih dahulu untuk melihat apakah instrumen adalah valid dan mewakili populasi. Pengujian ini digunakan untuk mempresentasikan setiap konstruk yang dapat diketahui dengan cara melihat convergent validity yang diukur dengan menggunakan nilai Average Variance Ectracted (AVE) sebagaimana nilai AVE harus $>0,5$ (Ghozali \& Latan, 2015). Seluruh konstruk yang digunakan dalam penelitian ini menunjukkan convergent validity yang baik. Setiap indikator pengukuran terhadap variabel penelitian memiliki nilai yang tidak sama, diketahui dari nilai outer loading berada di atas 0,6. Nilai outer loading pada Tabel 1 memperlihatkan bahwa pertanyaan 4 dari variabel daya saing (TIV4) yang tidak valid sehingga harus dieliminasi, sedangkan indikator pertanyaan lainnya sudah valid. 


\begin{tabular}{|c|c|c|c|c|}
\hline Item & $\begin{array}{c}\text { Akses ke } \\
\text { Keuangan (ACC) }\end{array}$ & Daya Saing (TIV) & $\begin{array}{c}\text { Budaya Keuangan } \\
\text { (CUL) }\end{array}$ & $\begin{array}{c}\text { Keputusan } \\
\text { Pembayaran } \\
(\mathrm{REY})\end{array}$ \\
\hline ACC1 & 0,871 & & & \\
\hline $\mathrm{ACC} 2$ & 0,828 & & & \\
\hline $\mathrm{ACC} 3$ & 0,819 & & & \\
\hline $\mathrm{ACC} 4$ & 0,850 & & & \\
\hline ACC5 & 0,810 & & & \\
\hline ACC6 & 0,744 & & & \\
\hline TIV1 & & 0,642 & & \\
\hline TIV2 & & 0,807 & & \\
\hline TIV3 & & 0,693 & & \\
\hline TIV5 & & 0,866 & & \\
\hline CUL1 & & & 0,864 & \\
\hline CUL2 & & & 0,850 & \\
\hline CUL3 & & & 0,867 & \\
\hline CUL4 & & & 0,816 & \\
\hline CUL5 & & & 0,780 & \\
\hline CUL6 & & & 0,881 & \\
\hline REY1 & & & & 0,830 \\
\hline REY2 & & & & 0,794 \\
\hline REY3 & & & & 0,787 \\
\hline REY4 & & & & 0,828 \\
\hline REY5 & & & & 0,741 \\
\hline REY6 & & & & 0,764 \\
\hline
\end{tabular}

Sumber: Data yang diolah

Untuk memastikan bahwa instrumen-instrumen variabel telah konsisten dan akurat, instrumen-instrumen tersebut diperiksa reliabilitasnya melalui nilai conbach's alpha. Dalam Tabel 2 menunjukkan bahwa semua variabel adalah reliabel, yaitu di atas 0,7. Kemudian nilai konstruk dari setiap konstruk lebih besar dari konstruk lainnya dan di atas nilai 0,7 , sehingga validitas diskriminan terpenuhi.

Tabel 2. Hasil pengujian Validitas dan Reliabilitas

\begin{tabular}{lcccc}
\hline & $\begin{array}{c}\text { Akses ke } \\
\text { Keuangan } \\
\text { (ACC) }\end{array}$ & $\begin{array}{c}\text { Daya Saing } \\
\text { (TIV) }\end{array}$ & $\begin{array}{c}\text { Budaya } \\
\text { Keuangan } \\
\text { (CUL) }\end{array}$ & $\begin{array}{c}\text { Keputusan } \\
\text { Pembayaran } \\
\text { (REY) }\end{array}$ \\
\hline Akses Keuangan & 0,821 & & & \\
Daya Saing & 0,368 & 0,757 & & \\
Budaya Keuangan & 0,423 & 0,297 & 0,844 & \\
Keputusan Pembayaran Kredit & 0,424 & 0,292 & 0,552 & 0,791 \\
Cronbach's Alpha & 0,904 & 0,763 & 0,919 & 0,882 \\
$\begin{array}{l}\text { Average Variance Extracted } \\
\text { (AVE) }\end{array}$ & 0,675 & 0,574 & 0,712 & 0,626 \\
\hline
\end{tabular}

Sumber: Data yang diolah 
Jepara merupakan salah satu kota kecil yang produktif, karena setidaknya ada 13 jenis industri kecil dan menengah yang berkembang (BPS Jepara, 2016). Industri kecil dan menengah tersebut antara lain furnitur, genteng, gerabah, kerajinan kayu, kerajinan rotan, konveksi dan bordir, mainan anak, makanan, monel, dan tenun ikat. Karakterisrik responden dan bisnisnya teringkas dalam Tabel 3 di bawah alinea ini. Sebagian besar responden memiliki usaha furnitur (29,7\%), ini karena Jepara sendiri merupakan kota ukir dan furnitur. Usaha yang dijalankan responden saat ini sebagian besar adalah usaha turun temurun. 27\% usaha yang berjalan selama 5-10 tahun dan selebihnya (73\%) berjalan lebih dari 10 tahun. Sedangkan, pemilik usaha didominasi oleh laki-laki $(77,5 \%)$ dan paling banyak berusia berkisar 40-49 tahun (30,9\%) dan 50-59 tahun (34,4\%). Usia-usia muda dan produktif yaitu usia 20-29 tahun hanya $12.3 \%$ dan usia 30-39 tahun hanya 14,0\%, sedangkan selebihnya berusia lanjut. Menurut tingkat pendidikan, sebagian besar responden berasal dari tingkat pendidikan rendah yaitu sekolah dasar sebanyak 34\%. Untuk yang pernah mengenyam pendidikan tinggi hanya 8\%, selebihnya dari SMP (26,3\%) dan SMA $(31,6 \%)$.

Tabel 3. Profil Responden dan Usaha yang Dijalankan

\begin{tabular}{|c|c|c|c|}
\hline Karakteristik & Kategori & Frekuensi & Persen $(\%)$ \\
\hline \multirow{2}{*}{ Jenis kelamin } & Laki-laki & 221 & 77,50 \\
\hline & Perempuan & 64 & 22,50 \\
\hline \multirow{6}{*}{ Usia (tahun) } & $20-29$ & 35 & 12,30 \\
\hline & $30-39$ & 40 & 14,00 \\
\hline & $40-49$ & 88 & 30,90 \\
\hline & $50-59$ & 98 & 34,40 \\
\hline & $60-69$ & 21 & 7,40 \\
\hline & $\geq 70$ & 3 & 1,10 \\
\hline \multirow{4}{*}{ Pendidikan terakhir } & SD-Sederajat & 97 & 34,00 \\
\hline & SMP-Sederajat & 75 & 26,30 \\
\hline & SMA-Sederajat & 90 & 31,60 \\
\hline & Diploma atau Sarjana (S-1) & 23 & 8,10 \\
\hline \multirow{10}{*}{ Jenis usaha } & Furnitur & 83 & 29,12 \\
\hline & Genteng & 69 & 24,21 \\
\hline & Gerabah & 3 & 1,05 \\
\hline & Kerajinan kayu & 24 & 8,42 \\
\hline & Kerajinan rotan & 15 & 5,26 \\
\hline & Konveksi dan bordir & 42 & 14,74 \\
\hline & Mainan anak & 6 & 2,11 \\
\hline & Makanan & 16 & 5,61 \\
\hline & Monel & 11 & 3,86 \\
\hline & Tenun ikat & 16 & 5,61 \\
\hline \multirow{5}{*}{ Lama usaha (tahun) } & $5-10$ & 77 & 27,00 \\
\hline & $11-15$ & 56 & 19,60 \\
\hline & $16-20$ & 57 & 20,00 \\
\hline & $21-25$ & 27 & 9,50 \\
\hline & $26-30$ & 27 & 9,50 \\
\hline
\end{tabular}




\begin{tabular}{ccccc}
\hline Karakteristik & & Kategori & Frekuensi & Persen (\%) \\
\hline & $31-35$ & & 13 & 4,60 \\
& $36-40$ & 14 & 4,90 \\
& $>40$ & 14 & 4,90 \\
\hline
\end{tabular}

Sumber: Data yang diolah

Berdasarkan Tabel 4 diperoleh nilai $R$-Square konstruk variabel dependen sebesar 0,272, ini mengindikasikan bahwa 27,2\% faktor yang menentukan akses ke keuangan UKM berasal dari daya saing, budaya keuangan, dan keputusan pembayaran kredit, selebihnya ditentukan dari faktor diluar model penelitian ini.

Tabel 4. Hasil R-Square

\begin{tabular}{lcc}
\hline & $R$ Square & $R$ Square Adjusted \\
\hline Akses ke Keuangan (ACC) & 0,279 & 0,272 \\
\hline
\end{tabular}

Sumber: Data yang diolah

Besarnya pengaruh variabel independen penelitian ini terhadap variabel dependen juga dapat dievaluasi menggunakan hasil uji $t$-statistic. Nilai yang hitung $t$-statistic dibandingkan dengan t-table sebesar 1,96 dengan nilai probabilitas 0,05. Hasil regresi dan t-statistic penelitian ini teringkas dalam Tabel 5. Dalam tabel tersebut dapat disimpulkan bahwa semua hipotesis penelitian diterima, baik itu hipotesis alternatif 1 (H1) yang mengatakan bahwa daya saing berpengaruh terhadap akses UKM ke keuangan; hipotesis alternatif 2 (H2) bahwa budaya keuangan berpengaruh terhadap akses UKM ke keuangan; dan hipotesis alternatif 3 (H3) bahwa keputusan pembayaran kredit berpengaruh terhadap akses UKM ke keuangan. Simpulan korelasi ini berdasarkan pada hasil t-statistic lebih dari 1,96 dan p-values kurang dari 0,05. Dengan demikian, pengaruh parsial variabel daya saing, budaya keuangan, dan keputusan pembayaran kredit terhadap akses ke keuangan adalah signifikan.

Tabel 5. Hasil Regresi dan Uji Hipotesis

\begin{tabular}{lccccc}
\hline & $\begin{array}{c}\text { Original } \\
\text { Sample }\end{array}$ & $\begin{array}{c}\text { Standard } \\
\text { Deviation }\end{array}$ & T-statistics & $p$-values & Keputusan \\
\hline TIV -> ACC & 0.234 & 0.053 & 4.421 & 0.000 & Diterima \\
CUL -> ACC & 0.226 & 0.076 & 2.973 & 0.003 & Diterima \\
REY -> ACC & 0.231 & 0.066 & 3.521 & 0.000 & Diterima \\
\hline
\end{tabular}

Sumber: Data diolah, 2020

Sebagaimana pernyataan Ahmedova (2015), bahwa kemakmuran bisnis UKM sangat ditentukan dari kemampuan daya saing UKM itu sendiri. Daya saing mendeskripsikan kondisi bisnis siap untuk bersaing dengan para pesaingnya di pasar termasuk terkait aksesibilitas pembiayaan. Hasil statistik ini menemukan bahwa daya saing berpengaruh terhadap akses UKM ke keuangan. Nilainya mengarah pada angka positif dan signifikan, ini berarti bahwa kemampuan daya saing yang tinggi dapat meningkatkan potensi UKM lebih 
mudah mengakses pembiayaan ke lembaga keuangan. Sesuai dengan hasil empiris yang menyebutkan daya saing dipandang sebagai potensi untuk mencapai produktivitas yang tinggi (Ahmedova, 2015; Laureti \& Viviani, 2011; Wysokińska, 2003). Potensi grow up produktivitas UKM mengindikasikan perusahaan dapat hidup normal diantara perusahaanperusahaan lainnya (pesaing) dalam satu bidang usaha. Sehingga UKM memiliki peluang lebih besar mengakses pembiayaan karena lembaga keuangan mengindikasi kontinuitas dari UKM tersebut.

Organisasi membentuk budaya dan budaya adalah organisasi itu sendiri (Van Der Post et al., 1998). Kalimat itu mendeskripsikan bahwa setiap organisasi membentuk atmosfer lingkungan kerja. Budaya kerja yang tumbuh menjadi kebiasaan dalam perusahaan akan berdampak pada aktivitas operasional perusahaan, baik itu kebiasaan baik yang mengarah pada peningkatan kinerja atau justru kebiasaan buruk yang mengakibatkan penurunan kinerja. Apalagi terkait dengan keuangan, yang notabennya merupakan bagian krusial keberlangsungan bisnis. Potensi kecurangan lebih besar ketika karyawan dihadapkan pada uang dalam jumlah yang besar sehingga manajemen dan pencatatan keuangan menjadi sangat penting. Budaya keuangan yang dibangun pemilik UKM dapat membantu mengurangi kecurangan dan kesejahteraan lebih terjamin. Seperti halnya yang disebutkan oleh Rumyantseva (2013) bahwa budaya keuangan merupakan kunci kesejahteraan keuangan dan produktivitas perusahaan yang melibatkan pengetahuan dan kemampuan hukum-ekonomi dalam pengambilan keputusan. Ketika kesejahteraan keuangan terjaga, maka potensi aksesibilitas UKM terbuka lebih lebar. Sesuai dengan hasil empiris penelitian ini, bahwa budaya keuangan berpengaruh positif terhadap akses UKM ke keuangan.

Selanjutnya, statistik penelitian ini menemukan adanya pengaruh positif dari keputusan pembayaran kredit terhadap akses UKM ke keuangan. Hasil ini sejalan dengan McHugh \& Ranyardn $(2012,2016)$ yang menemukan bahwa keputusan pembayaran pinjaman memiliki efek signifikan terhadap tingkat pembayaran pinjaman. Tingkat pembayaran pinjaman dapat menggambarkan kemampuan debitur membayar pinjamannya. Keputusan pembayaran cicilan secara rutin menunjukkan UKM memenuhi kewajibannya dengan baik sehingga tingkat pembayaran pinjamannya terjamin. Rasa kekhawatiran pembayaran pinjaman di masa depan dapat teratasi dengan konsistensi pembayaran pinjaman. Dengan demikian, trust lembaga keuangan meningkat dan akses ke keuangan lebih mudah. 


\section{KESIMPULAN DAN SARAN}

Akses ke keuangan merupakan fitur penting dalam operasi bisnis UKM. Berbeda dari perusahaan besar, UKM menunjukkan personalisasi karena perkembangannya bergantung pada pengusaha yang sekaligus adalah pemilik dan pendiri. Efek personalisasi tersebut yang menyebabkan keraguan bank terhadap perilaku pembayaran kembali kredit yang diambil. Hasil penelitian ini menunjukkan bahwa akses UKM ke keuangan dipengaruhi oleh faktor daya saing, budaya keuangan, dan keputusan pembayaran kredit. Temuan ini memberikan literasi di bidang keuangan terkait dengan aksesibilitas UKM ke pembiayaan dan keputusan pembayaran kredit, daya saing, serta budaya keuangan. Dapat disimpulkan bahwa kapasitas (daya saing dan budaya) dan kemauan (keputusan) pembayaran pinjaman menentukan aksesibilitas UKM ke pembiayaan. Akan tetapi, di sisi lain, UKM masih mengeluhkan sulitnya akses mereka pada pembiayaan di lembaga keuangan konvensional. Padahal, suntikan dana eksternal ini dapat digunakan UKM untuk mengembangkan usahanya dan memperluas pasar mereka. Penelitian ini tidak lepas dari keterbatasan, namun keterbatasan itu tidak mengurangi kualitas hasil penelitian ini. Keterbatasan yang terjadi selama di lapangan adalah sulitnya memperoleh kesediaan responden untuk bekerja sama dalam penelitian. Selain itu, beberapa responden mengalami kesulitan memahami beberapa pertanyaan dalam kuesioner sehingga perlu adanya pendampingan dan penjelasan. Penelitian selanjutnya dapat mengembangkan instrumen pengukuran variabel-variabel dalam penelitian ini berdasarkan kajian studi empiris dan memperluas sampling berdasarkan jenis usaha dan wilayah. Pengujian hubungan variabel-variabel lain terkait dengan UKM juga dapat dikaji lebih lanjut, seperti keterkaitan budaya keuangan terhadap kinerja keuangan dan produktivitas.

\section{REFERENSI}

Adomako, S., Danso, A., \& Damoah, J. O. (2015). The Moderating Influence of Financial Literacy on The Relationship Between Access to Finance and Firm Growth in Ghana. Venture Capital, 18(1), 43-61. https://doi.org/10.1080/13691066.2015.1079952

Ahiawodzi, A. K., \& Adade, T. C. (2012). Access to Credit and Growth of Small and Medium Scale Enterprise in the Ho Municipality of Ghana. British Journal of Economics, Finance and Management Sciences, 6(2), 34-51.

Ahmedova, S. (2015). Factors for Increasing the Competitiveness of Small and MediumSized Enterprises (SMEs) in Bulgaria. Procedia - Social and Behavioral Sciences, 195, 1104-1112. https://doi.org/10.1016/j.sbspro.2015.06.155 
Angilella, S., \& Mazzù, S. (2015). The Financing of Innovative SMEs: A Multicriteria Credit Rating Model. European Journal of Operational Research, 244(2), 540-554. https://doi.org/https://doi.org/10.1016/j.ejor.2015.01.033

Anton, S. A., Muzakan, I., Muhammad, W. F., Syamsudin, \& Sidiq, N. P. (2015). An Assessment of SME Competitiveness in Indonesia. Journal of Competitiveness, 7(2), 60-74. https://doi.org/10.7441/joc.2015.02.04

Arenius, P., \& Autio, E. (2006). Financing of Small Businesses: Are Mars and Venus More Alike than Different? Venture Capital, 8(2), 93-107. https://doi.org/10.1080/13691060500433793

BPS Jepara. (2016). Tabel Dinamis Banyaknya Unit Usaha dan Tenaga Kerja Dirinci. Https://Jeparakab.Bps.Go.Id/.

Breuer, W., \& Quinten, B. (2009). Cultural Finance. Available at SSRN 1282068. https://doi.org/http://dx.doi.org/10.2139/ssrn.1282068

Carvalho, L., \& Costa, T. (2014). Small and Medium Enterprises (SMEs) and Competitiveness: An Empirical Study. Management Studies, 2(2), 88-95.

Ceptureanu, S. lon. (2015). Competitiveness of SMEs. Business Excellence and Management, $5(2), 55-67$.

Csiszárik-kocsir, Á., Varga, J., \& Fodor, M. (2016). The Value Based Analysis of the Financial Culture. The Journal of Macrotrends in Social Science, 2(1), 89-100.

Demirgüç-Kunt, A., Honohan, P., \& Beck, T. (2008). Finance for All: Policies and Pitfalls in Expanding Access. The World Bank.

Fowowe, B. (2017). Access to Finance and Firm Performance: Evidence from African Countries. Review of Development Finance, 7(1), 6-17. https://doi.org/10.1016/j.rdf.2017.01.006

Gazanchyan, N. S., Hashimzade, N., Rodionova, Y., \& Vershinina, N. (2017). Gender, Access to Finance, Occupational Choice, and Business Performance, CESifo Working Paper, No. 6353, Center for Economic Studies and Ifo Institute (CESifo), Munich.

Ghozali, I., \& Latan, H. (2015). Partial Least Squares: Konsep, Teknik dan Aplikasi Menggunakan Program SmartPLS 3.0 (2nd ed.). Badan Penerbit Universitas Diponegoro.

Harash, E., Al-timimi, S., \& Alsaadi, J. (2014). The Influence of Finance on Performance of Small and Medium Enterprises ( SMES ). International Journal of Engineering and Innovative Technology, 4(3), 161-167. 
Ikasari, N., Sumransat, T., Eko, U., \& Kusumastuti, R. (2016). Access of Small and Medium Enterprises to Finance in Rural Areas: Case of Indonesia and Thailand. International Journal of Economics and Management Engineering, 10(5), 1661-1668.

Ismanto, H., \& Diman, T. (2014). Analisis Efektivitas Pemberian Pinjaman Program Pembiayaan UMKM oleh Koperasi. Jurnal Economia, 10(2), 148-164. https://doi.org/10.21831/economia.v10i2.7541

Karaev, A., Koh, S. C. L., \& Szamosi, L. T. (2007). The Cluster Approach and SME Competitiveness: A Review. Journal of Manufacturing Technology Management, 18(7), 818-835. https://doi.org/10.1108/17410380710817273

Laureti, T., \& Viviani, A. (2011). Competitiveness and Productivity: A Case Study of Italian Firms. Applied Economics, 43(20), 2615-2625.

https://doi.org/10.1080/00036840903357439

Lee, N., Sameen, H., \& Cowling, M. (2015). Access to Finance for Innovative SMEs Since The Financial Crisis. Research Policy, 44(2), 370-380.

Lee, N., Sameen, H., \& Martin, L. (2013). Credit and the Crisis: Access to Finance for Innovative Small Firms Since the Recession (Issue June).

Machmud, Z., \& Huda, A. (2011). SMEs' Access to Finance: An Indonesia Case Study. In ERIA Research Project Report 201014 (pp. 261-290).

McHugh, S., \& Ranyard, R. (2012). Credit Repayment Decisions: The Role of Long-Term Consequence Information, Economic and Psychological Factors. Review of Behavioral Finance, 4(2), 98-112. https://doi.org/10.1108/19405971211284880

McHugh, S., \& Ranyard, R. (2016). Consumers' Credit Card Repayment Decisions: The Role of Higher Anchors and Future Repayment Concern. Journal of Economic Psychology, 52(February), 102-114. https://doi.org/10.1016/j.joep.2015.12.003

Mertzanis, C. (2017). Marketing Financial Services and Products in Different Cultural Environments. In Information Resources Management Association (Ed.), Risk and Contingency Management: Breakthroughs in Research and Practice: Breakthroughs in Research and Practice (pp. 134-160). IGI Global.

Mutegi, H. K., Njeru, P. W., \& Ongesa, N. T. (2015). Financial Literacy and its Impact on Loan Repayment by Small and Medium Enterpreneurs. International Journal of Economics, Commerce and Management, III(3), 1-28. http://ijecm.co.uk/

Rumyantseva, A. (2013). The Impact of Financial Culture on The Operating Rates. SaintPetersburg University of Management and Economics, Saint-Petersburg, Russia, 169176. 
Scott, J. M., \& Irwin, D. (2007). How SME Owners' Characteristics Influences External Advice and Access to Finance. https://doi.org/10.1108/17410391111097438

Siddiqui, M. A. (2017). The Effects of Entrepreneurs Characteristics on Loan Repayment Behaviour of MSMEs. Journal of Management and Technology, 13(2), 16-21.

Statman, M. (2008). Countries and Culture in Behavioral Finance. FA Institute Conference Proceedings Quarterly. Vol. 25. No. 3, 38-44.

Treichel, M. Z., \& Scott, J. A. (2006). Women-owned Businesses and Access to Bank Credit: Evidence from Three Surveys Since 1987. Venture Capital, 8(1), 51-67. https://doi.org/10.1080/13691060500453726

Van Der Post, W. Z., De Coning, T. J., \& Smit, E. V. D. M. (1998). The Relationship Between Organisational Culture and Financial Performance: Some South African Evidence. South African Journal of Business Management, 29(1), 30-40. https://doi.org/10.4102/sajbm.v29i1.768

Venturelli, V. (2008). Access to Finance of Innovative SMEs. In Bridging the Equity Gap for Innovative SMEs (pp. 17-28). Palgrave Macmillan.

Wang, W. (2012). How The Small and Medium-Sized Enterprises' Owners' Credit Features Affect The Enterprises'credit Default Behavior? E3 Journal of Business Management and Economics, 3(2), 090-095.

https://econpapers.repec.org/article/etrseries/v_3a3_3ay_3a2012_3ai_3a2_3ap_3a090095.htm

Wellalage, N., \& Locke, S. (2017). Access to Credit by SMEs in South Asia: Do Women Entrepreneurs Face Discrimination. Research in International Business and Finance, 41(October), 336-346. https://doi.org/10.1016/j.ribaf.2017.04.053

Wysokińska, Z. (2003). Competitiveness and Its Relationships with Productivity and Sustainable Development. Fibres \& Textiles in Eastern Europe, 11(3), 11-14. http://www.fibtex.lodz.pl/42_06_11.pdf

Zsótér, B. (2018). The Aspects of Financial Culture Among Young Adults. Ekonomske Ideje i Praksa, 30, 51-71. 